\title{
Crude oil He and Ar isotopic characteristics and their geochemical significance: an example from the Gangxi oil field in the Huanghua depression
}

\author{
Zhang Xiaobao $\left({ }^{1}\right)$, Ma Liyuan $\left({ }^{1}\right)$, Chen Jianping $\left({ }^{2}\right)$, Sun Mingliang $\left({ }^{1}\right)$, \\ Tu Jianqi $\left({ }^{2}\right)$, Li Xiufen $\left({ }^{1}\right)$ and Song Chenpeng $\left({ }^{1}\right)$ \\ (1) State Key Laboratory of Gas Geochemistry, Lanzhou Institute of Geology, \\ Chinese Academy of Sciences, Gansu, People's Republic of China \\ $\left.{ }^{2}\right)$ The Research Institute of Exploration and Development, \\ China National Petroleum Corporation, Beijing, People's Republic of China
}

\begin{abstract}
Sampled from the Gangxi oil field in the Huanghua depression, Bohaiwan Basin, the crude oil He and Ar isotopic compositions and their geochemical significance were investigated. The result shows that i) the ${ }^{3} \mathrm{He} /{ }^{4} \mathrm{He}$ values of the six oil samples free from air contamination indicate a mantle helium contribution ranging between $13.9 \%$ and $32.8 \%$ and averaging $24.1 \%$, which means that the Gangxi oil field once had a tectonic background of the mantle-derived helium input and higher geothermal flow with an average of $75.0 \mathrm{mWm}^{-2}$; ii) deduced from the ${ }^{40} \mathrm{Ar} /{ }^{36} \mathrm{Ar}$ aging effect the Gangxi oil should be derived from the Tertiary; iii) water injection is the main reason for the air contamination for the Gangxi oil noble gases and the relations between ${ }^{3} \mathrm{He} /{ }^{4} \mathrm{He}$ and ${ }^{4} \mathrm{He} /{ }^{20} \mathrm{Ne}$ as well as ${ }^{40} \mathrm{Ar} /{ }^{36} \mathrm{Ar}$ and ${ }^{4} \mathrm{He} /{ }^{20} \mathrm{Ne}$ are of an applicative potential in estimating the water injection effect and the connectivity of producing formations. The search for the crude oil He and Ar isotopes provides a new approach to inferring natural gas and oil sources, tectonic backgrounds, geothermal flow and water injection effect.
\end{abstract}

Key words crude oil - noble gas tracing - Gangxi oil field - Huanghua depression

\section{Introduction}

Noble gases in natural gas have been widely applied in identifying natural gas genesis (Jenden et al., 1989; Xu Yongchang et al., 1996a), migration (Torgersen and Kennedy, 1999; Bat-

Mailing address: Dr. Zhang Xiaobao, State Key Laboratory of Gas Geochemistry, Lanzhou Institute of Geology, Chinese Academy of Sciences, 324 Donggang West Road Lanzhou, 730000 Gansu, People's Republic of China; email: zhangs@sun.ihep.ac.cn tani et al., 2000), gas source tracing (Xu Yongchang et al., 1998), interaction of the crust with the mantle (Dai Jinxing et al., 1995; Tao Mingxing et al., 1996), tectonics (Oxburgh and O'Nions, 1987; Gulec et al., 2002), and geothermal flow (Polyak et al., 1985). Since crude oil is closely related to natural gas in formation, migration, and pool-forming of hydrocarbons, it could be deduced that detailed information on petroleum geology also exists in crude oil noble gases. However, it is a pity so far that little research has been done on the geochemistry of crude oil noble gases (Pinti and Marty, 1995). The purpose of this paper is to report $\mathrm{He}$ and $\mathrm{Ar}$ isotopic values of the oil-dissolved gases and to discuss their application in tracing natural gas source, tectonics, geothermal flow and oil 


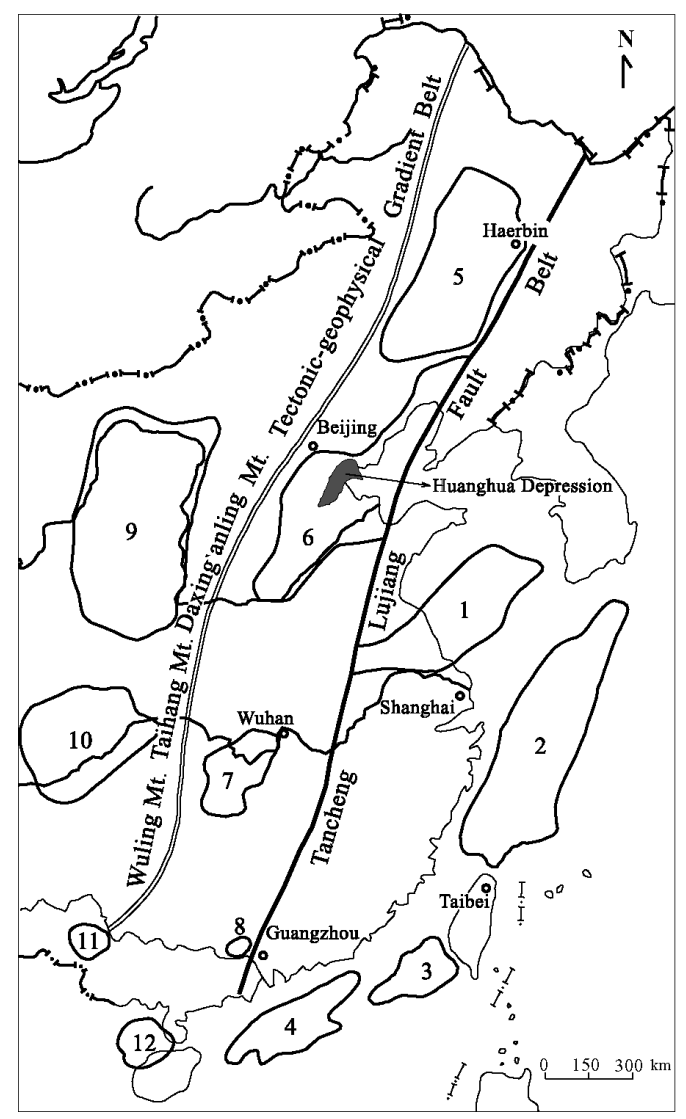

Fig. 1. Tectonic location of the Huanghua Depression in the Huaxia rift system, China (Ishibashi et al., 2002): 1 - Subei-South Huanghai Basin; 2 - Donghai Basin; 3 - Taixinan Basin; 4-Zhujiangkou Basin; 5 - Songliao Basin; 6-Bohaiwan Basin; 7 - Jianghan Basin; 8 -Sanshui Basin; 9-Ordos Basin; 10 - Sichuan Basin; 11 - Baise Basin.

source as well as their potential in identifying the water injection effect in the Gangxi oil field of the Huanghua depression.

\section{Geological background}

The Indo-China movement during the MesoCenozoic is thought to be a very important one which greatly changed the Pre-Mesozoic tectonic framework of China by subduction of the Pacific plate under the Asia-Euro plate (Tao Mingxing et al., 1996; Xu Yongchang et al., 1998). After the movement China could be tectonically classified into the Eastern Rift Tectonically Active Area, the Middle Craton Tectonically Stable Area, the Western Tectonically Substable Area, and the Qinghai-Tibet Plate Collision Compression Area (Tao Mingxing et al., 1996; Xu Yongchang et al., 1998), of these areas the Eastern Rift Tectonically Active Area could be further separated into the Near-shore Rift System and the Cathaysion Rift System by the Tancheng-Lujiang deep fault belt (Tao Mingxing et al., 1996; Xu Yongchang et al., 1998) (fig. 1).

The Near-shore Rift System is located to the east of the Tancheng-Lujiang deep fault belt and the Cathaysion Rift System to the west. Many petroleum-bearing basins distribute in these two systems. Many mantle helium anomalies, which are considered to be associated with the Tancheng-Lujiang deep fault belt and mantle de-

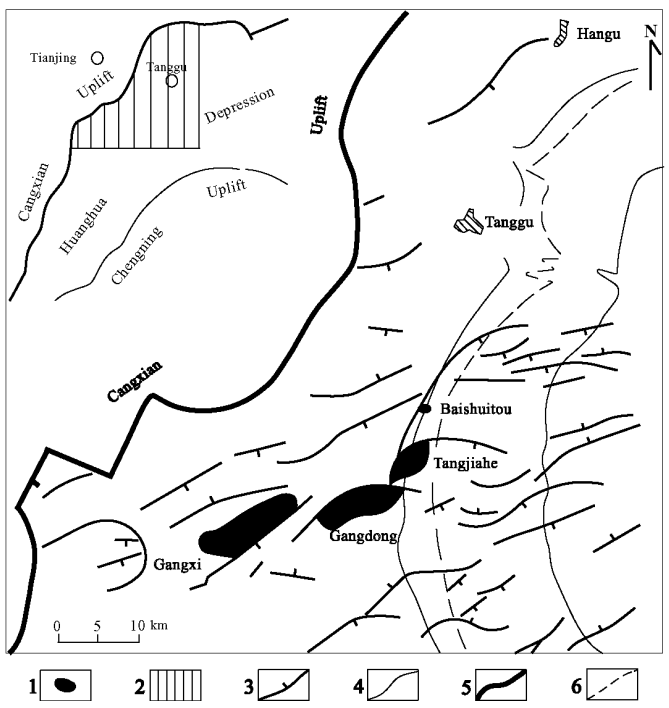

Fig. 2. Tectonic position of the Gangxi oil field in the Huanghua depression (Song Mingliang, 1991): 1 - oil field; 2 - studied area; 3 - fault; 4 - present shoreline; 5 - boundary of depression; 6 - present $5 \mathrm{~m}$ shoreline. 


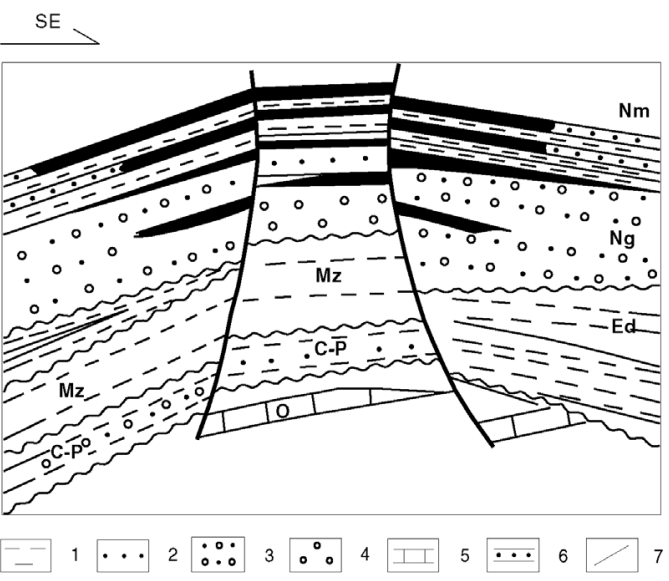

Fig. 3. Cross section of the Gangxi oil field (Song Mingliang, 1991): Nm-Upper Tertiary Minghuazhen formation; Ng-Upper Tertiary Guantao formation; Ed - Lower tertiary Dongying formation; $\mathrm{Mz}-$ Mesozoic; C-P - Carbo-Permian; O - Ordovician; 1 - mudstone; 2 - sandstone; 3 - sandy conglomerate; 4 - conglomerate; 5 - limestone; 6 - oil; 7 - fault.

gassing, have been found in natural gases of these basins (Tao Mingxing et al., 1996; Xu Yongchang et al., 1998). Of which the Bohaiwan Basin is located in the Huaxia rift system while the Huanghua depression is a tectonic division of the basin (fig. 1). The oil in the Huanghua depression is mainly derived and reservoired in the Tertiary. The Shahejie formation and the Dongyin formation developed in the Lower Tertiary and the Guantao formation and the Minghuazheng formation in the Upper Tertiary from the lower to upper. The oil source rock is mainly distributed in the Shahejie formation. The Gangxi oil field is situated in the Huanghua depression (fig. 2). The oil field occurs in a drape anticline trap formed by continuous arching of the Pre-Tertiary base rocks and being covered by the Tertiary (fig. 3).

Oils of the oil field are preserved and sealed in the Upper Tertiary Guantao formation and Minghuazheng formation. The evidence of biomarkers in oils shows that the oil is chiefly derived from the Lower Tertiary Shahejie formation source rocks.

\section{Experiment}

Glass was used to make a sample tube shown in fig. 4. The tube has two dependable airproof valves with the same shape on both sides and a volume of $100 \mathrm{ml}^{3}$, with a $5 \mathrm{~mm}$ inner diameter and a $7 \mathrm{~mm}$ outer diameter of the piston tube. The upstream end of the tube is linked with a latex tube connecting with a mouth of a wellhead. The two valves of the tube were open first, then the switch of the mouth of the wellhead was opened and oil was allowed to flow through the tube. To remove air contamination, the tube was washed by oil for $5 \mathrm{~min}$, then the switch of the wellhead and the valve on the downstream end of the sampling tube were closed simultaneously, and finally the valve on the upstream end of the tube was closed. After sampling, the two valves of the tube were fixed using an adhesive plaster. Ten oil samples were collected from the Gangxi oil field. To correlate the oil with natural gas in noble gas geochemistry, seven natural gas samples were collected from the Lower Tertiary Dongying formation in the Tangjiahe oil field, the Baishuitou oil field, and the first member of the Shahejie formation and the Guantao formation and the Minghuazheng formation in the Madong oil field, respectively. Of the samples the oils and natural gases of the Xi 3-7-1 well and the Xi 34-5-1 well were collected from the same productive formations.

In the laboratory a glass tube filled with oils linked with a vacuumed empty glass container, was then connected with the sample inlet of a VG5400 mass spectrograph. Then the downstream end of the vacuumed glass container was opened and the oil in the glass container was degassed. After the oil-dissolved gas was exposed to a zircon-aluminum getter, a titanium sponge

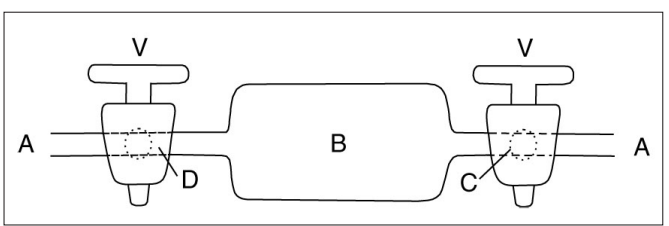

Fig. 4. Sample glass bottle. A - outlet tube; B chamber; $\mathrm{C}$ - piston hole; $\mathrm{D}$ - piston tube; $\mathrm{V}$ - valve. 


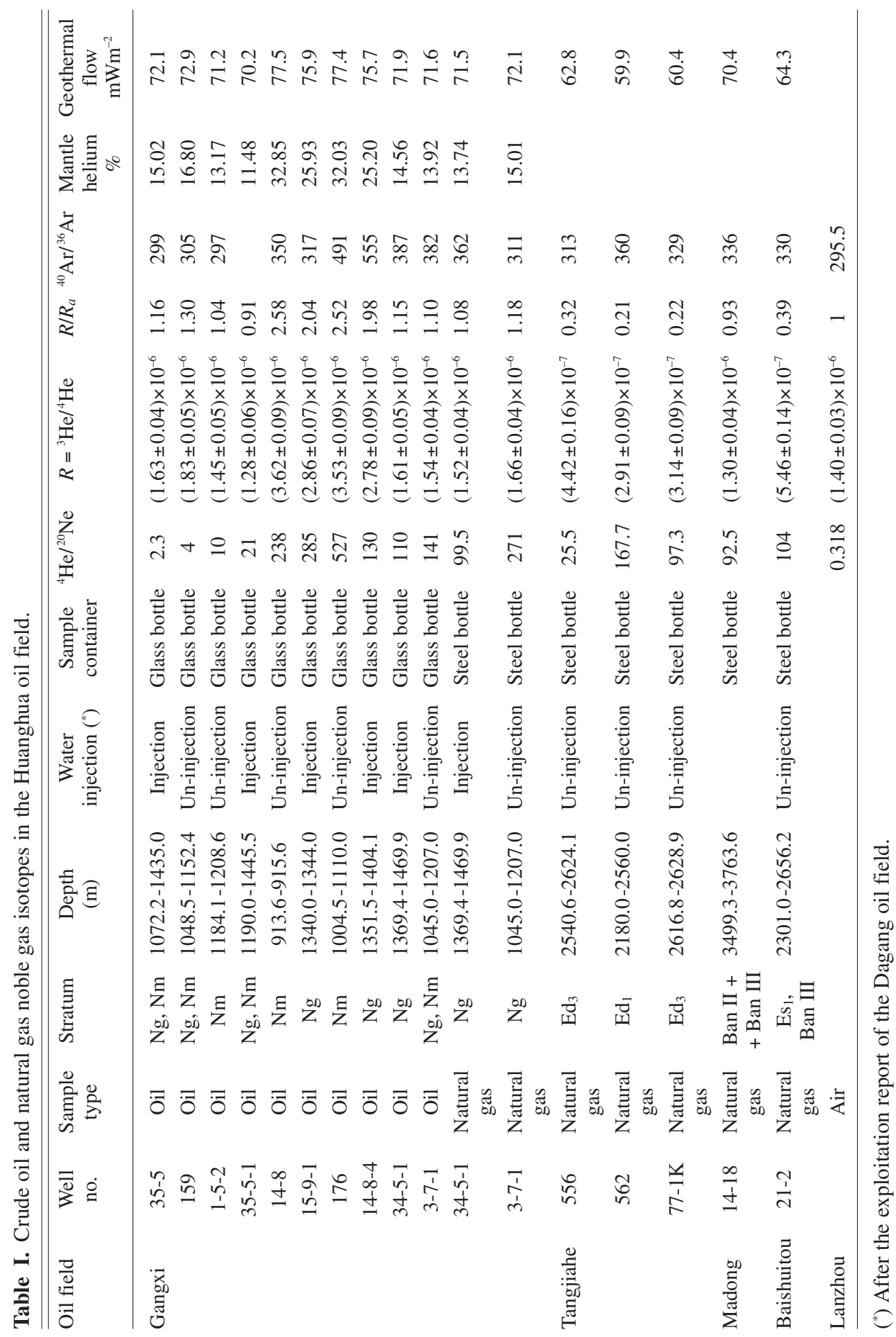


pump removed the active gases such as $\mathrm{H}_{2}, \mathrm{O}_{2}$, $\mathrm{H}_{2} \mathrm{O}$ and hydrocarbon gases. Ar was then trapped in a charcoal trap held at a liquid $\mathrm{N}_{2}$ temperature. However, pure $\mathrm{He}$ was admitted to the analytical system of the mass spectrometer. Resolving power of about 600 at $1 \%$ of the peak height was attained for complete separation of the ${ }^{3} \mathrm{He}^{+}$beam from $\mathrm{HD}^{+}$and $\mathrm{H}_{3}{ }^{+}$beams in the system. Then Ar was desorbed from the charcoal finger by warming and was also allowed into the analytical system. The standard gas was measured before analyzing samples; measurement results of samples were normalized to the standard gas, which was made by purifying air and periodically examined by air during measurement. All the analytical results are reported on the basis of the atmospheric values internationally used as standard, whose ${ }^{3} \mathrm{He} /{ }^{4} \mathrm{He}$ ratio is $1.40 \times 10^{-6}$, and ${ }^{40} \mathrm{Ar} /{ }^{36} \mathrm{Ar}$ ratio is 295.5. All the results of helium were given in the ${ }^{3} \mathrm{He} /{ }^{4} \mathrm{He}$ ratio and $R / R_{a}$ ratio where $R$ is the ${ }^{3} \mathrm{He} /{ }^{4} \mathrm{He}$ ratio of the sample and $R_{a}$ is that of air. The precise description of the measurement has been published (Song Mingliang, 1991; Song Mingliang, 1995; Xu Yongchang et al., 1998). The results of the measurement are listed in table I.

It should be emphasized that based on our practice the samples collected using the method described above should be prepared and analyzed as quickly as possible, because the samples could be air contaminated if they are collected after more than 15 days.

\section{Discussion}

\section{1. ${ }^{3} \mathrm{Hel}{ }^{4} \mathrm{He}$ versus ${ }^{4} \mathrm{He} /{ }^{20} \mathrm{Ne}$}

The two stable isotopes of helium, ${ }^{3} \mathrm{He}$ and ${ }^{4} \mathrm{He}$, have different origins. ${ }^{3} \mathrm{He}$ is essentially primordial and retained in the Earth's interior at the time of its formation whereas ${ }^{4} \mathrm{He}$ is mainly produced in the crust by the decay of $\mathrm{U}$ - and Th-series isotopes. The different layers of the Earth have different helium isotopic values. The atmospheric helium (A) has a ${ }^{3} \mathrm{He} /{ }^{4} \mathrm{He}$ ratio of $1.384 \pm 0.0004 \times 10^{-6}$ (Clarke et al., 1976), the crust helium (C) has a ${ }^{3} \mathrm{He} /{ }^{4} \mathrm{He}$ ratio $2 \times 10^{-8}$, and the mantle helium (including type $\mathrm{M}$ and type $\mathrm{P}$ ) has a ${ }^{3} \mathrm{He} /{ }^{4} \mathrm{He}$ ratio greater than $1.1 \times 10^{-5}$ (Kaneoka and Takaota, 1985). Therefore, ${ }^{3} \mathrm{He} /{ }^{4} \mathrm{He}$ could be used to trace helium sources. Generally, ${ }^{4} \mathrm{He} /{ }^{20} \mathrm{Ne}$ could be utilized to value the degree of air contamination in natural gases (Wakita et al., 1990). Through the search for ${ }^{3} \mathrm{He} /{ }^{4} \mathrm{He}$ and ${ }^{4} \mathrm{He} /{ }^{20} \mathrm{Ne}$, the source of helium could be discussed after the magnitude of air contamination has been estimated.

Figure 5 shows the relation of ${ }^{3} \mathrm{He} /{ }^{4} \mathrm{He}$ and ${ }^{4} \mathrm{He} /{ }^{20} \mathrm{Ne}$ of the Gangxi oils. In order to make a correlation, fig. 5 also shows the $\mathrm{He}$ and Ar isotopic data of natural gases from the Gangxi oil field and other oil fields in the Huanghua depression. Table I demonstrates that the oils and natural gases from the same productive formations as the $\mathrm{Xi} 3-7-1$ well and the $\mathrm{Xi} 34-5-1$ well

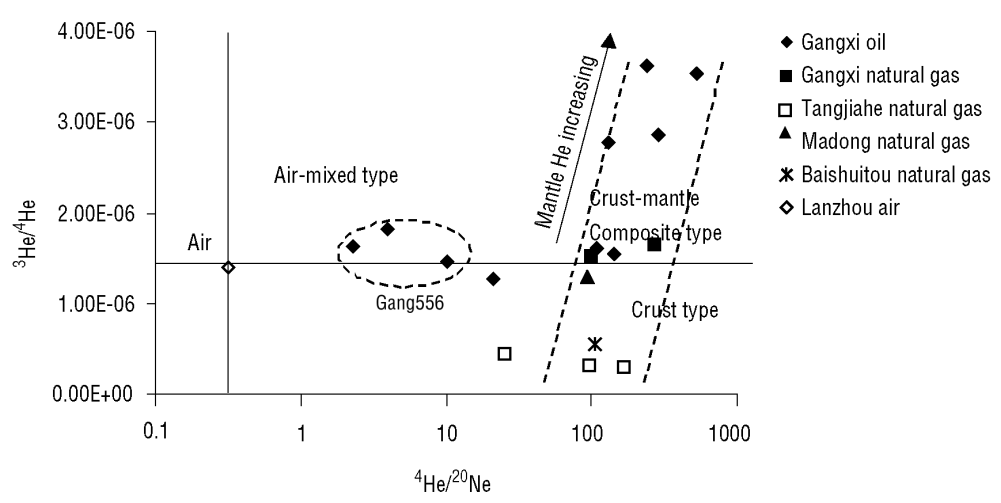

Fig. 5. Plot of ${ }^{3} \mathrm{He} /{ }^{4} \mathrm{He}$ versus ${ }^{4} \mathrm{He} /{ }^{20} \mathrm{Ne}$ of the crude oils from the Gangxi oil field. 
have a similar distribution of $\mathrm{He}$ and $\mathrm{Ar}$ isotopes, suggesting that the correlation of the crude oil $\mathrm{He}$ and $\mathrm{Ar}$ isotopes with the natural gas $\mathrm{He}$ and Ar is feasible. Table I and fig. 5 display that the noble gases in natural gases and crude oils could be divided into the crust-mantle composite type, the crust type and the air-mixed type based on ${ }^{3} \mathrm{He} /{ }^{4} \mathrm{He}$ and ${ }^{4} \mathrm{He} /{ }^{20} \mathrm{Ne}$ ratios.

\subsubsection{Crust-mantle composite type}

The ${ }^{4} \mathrm{He} /{ }^{20} \mathrm{Ne}$ ratio of this type of noble gases ranges from 99.5 to 527.0, averaging 225.2 (8). Most of the samples have ${ }^{4} \mathrm{He} /{ }^{20} \mathrm{Ne}$ values three orders of magnitude greater than that of air $\left({ }^{4} \mathrm{He} /{ }^{20} \mathrm{Ne}=0.318\right)$ indicating that air contamination is negligible to the ${ }^{3} \mathrm{He} /{ }^{4} \mathrm{He}$ ratios of the samples. The ${ }^{3} \mathrm{He} /{ }^{4} \mathrm{He}$ ratios of these samples vary from $1.52 \times 10^{-6}$ to $3.62 \times 10^{-6}$ with an average of $2.39 \times 10^{-6}(8)$. The $R / R_{a}$ ratios (where $R / R_{a}$ represents a ${ }^{3} \mathrm{He} /{ }^{4} \mathrm{He}$ ratio of a sample to that of air) of these samples ranges from 1.1 to 2.6 with a mean value of 1.7 (8). These show a mantle helium contribution. Based on the calculation formula (Xu Yongchang et al., 1998) of the mixed percent of the crust-mantle end members, the percentage of the mantle-derived helium of these samples ranges from 13.7 to $32.8 \%$, averaging $21.7 \%$. The noble gases of the six oil samples from the Gangxi oil fields are attributed to this type (table I and fig. 5).

The basic conditions (Dai Jinxing et al., 1995; Tao Mingxing et al., 1996; Xu Yongchang et al., 1998) for the input of mantle helium into petroleum-bearing basins include that i) the mantle bursts upward and the crust thins, ii) deep faults develop, resulting in mantle degassing and serving as a passage for mantle helium migration. The existence of the mantle-derived helium in the Gangxi oils of the Huanghua depression indicates that the oil field is of the above-mentioned tectonic conditions. Since the Mesozoic the mantle underlying the petroleum-bearing basins in the Cathaysion Rift Belt and the Near-shore Rift Belt in eastern China (fig. 1) has uplifted and the crust has notably thinned, halfgraben-like basins have formed in the shallow crust and expanding faults have developed in the basins. In the mantle cut by the Tancheng-Lujiang deep fault belt located between the Cathaysion Rift Belt and the Near-shore Rift Belt, the pressure decreases due to deep cutting of the fault belt and largescale mantle degassing occurs. In addition the Tancheng-Lujiang deep fault belt and its accessary base faults provide the migration of the mantle helium with passages. Therefore, a series of mantle helium anomalies $\left(R / R_{a}>1\right)$, even some mantle helium commercial accumulations (Xu Yongchang et al., 1996a), are found in the basins or depressions on both sides of or in the fault belt. The Huanghua depression is located in the Cathaysion rift belt, west of the fault belt, therefore, it is also of the tectonic background for the input of the mantle-derived helium (Dai Jinxing et al., 1995; Tao Mingxing et al., 1996; Xu Yongchang et al., 1998).

Similar to the natural gas ${ }^{3} \mathrm{He} /{ }^{4} \mathrm{He}$ ratio, the crude oil ${ }^{3} \mathrm{He} /{ }^{4} \mathrm{He}$ ratio could also be used to estimate the value of geothermal flow. Geothermal flow directly indicates the heat in the Earth, and it mainly consists of radiogenic heat in the crust and the heat from the upper mantle. The crude oil ${ }^{3} \mathrm{He} /{ }^{4} \mathrm{He}$ ratio is also associated with the crust radio elements and mantle matter. Therefore, the crude oil ${ }^{3} \mathrm{He} /{ }^{4} \mathrm{He}$ ratio can be used to indicate geothermal flow as well.

Table I lists values of geothermal flow in the Gangxi oil field, and then calculates using the relation formula, $q=6.993 \ln \left({ }^{3} \mathrm{He} /{ }^{4} \mathrm{He}\right)+165.16$ (Polyak et al., 1985), between geothermal flow (q) and crude oil ${ }^{3} \mathrm{He} /{ }^{4} \mathrm{He}$ ratios.

Table I demonstrates that the values of geothermal flow range from $71.6 \mathrm{mWm}^{-2}$ to $77.5 \mathrm{mWm}^{-2}$, averaging $75.0 \mathrm{mWm}^{-2}$ (6), which are coincident with the higher geothermal flow in the petroleum-bearing basins in eastern China (Polyak et al., 1985). Geothermal flow data are of important reference value to thermal evolution of source rocks, petroleum formation and petroleum resource assessment.

\subsubsection{Crust type}

This type of noble gases in oils has ${ }^{4} \mathrm{He} /{ }^{20} \mathrm{Ne}$ values ranging from 25.5 to 167.7 and averaging 97.4 (5), most of them are three orders of 
magnitude higher than that of air $\left({ }^{4} \mathrm{He} /{ }^{20} \mathrm{Ne}=\right.$ $=0.318$ ), suggesting a negligible mixture of air. The ${ }^{3} \mathrm{He} /{ }^{4} \mathrm{He}$ ratios of the oils range from $2.91 \times 10^{-7}$ to $1.30 \times 10^{-6}$, averaging $5.79 \times 10^{-7}$ (5), while the $R / R_{a}$ ratios from 0.2 to 0.9 , averaging 0.4 (5). These are characteristic of a dominant crust radiogenic origin with a minor contribution of the mantle. The natural gases from the Tangjiahe, Madong and Baishuitou oil field are attributed to this type, showing that these oil fields have no favorable conditions of the input of the mantle helium.

Additionally based on the calculated results of the relation formula between geothermal flow (q) and ${ }^{3} \mathrm{He} /{ }^{4} \mathrm{He}$ ratios, the geothermal flow values of these fields are lower than those of the Gangxi oil field, ranging from $59.9 \mathrm{mWm}^{-2}$ to $70.4 \mathrm{mWm}^{-2}$, averaging $63.6 \mathrm{mWm}^{-2}$ (5). In fig. 5 the ${ }^{3} \mathrm{He} /{ }^{4} \mathrm{He}$ and ${ }^{4} \mathrm{He} /{ }^{20} \mathrm{Ne}$ ratios of the crustmantle composite type and the crust type constitute a positively linear correlation, reflecting the increase in the mantle helium input.

\subsubsection{Air-mixed type}

Different from the above crust-mantle composite type and the crust type, the ${ }^{4} \mathrm{He} /{ }^{20} \mathrm{Ne}$ ratios of this type of noble gases ranges from 2.3 to 21.0, averaging 9.3 (4), which are only one to two orders of magnitude larger than that of air (Air ${ }^{4} \mathrm{He} /{ }^{20} \mathrm{Ne}=0.318$ ). This in combination with the ${ }^{40} \mathrm{Ar} /{ }^{39} \mathrm{Ar}$ distribution near to the air ${ }^{40} \mathrm{Ar} /{ }^{39} \mathrm{Ar}$ ratio, suggests that this type of the noble gases in oils is characteristic of the mixture of the crust noble gas with the air noble gas. The oil for the Xi 35-51 well has a ${ }^{3} \mathrm{He} /{ }^{4} \mathrm{He}$ value of $1.28 \times 10^{-6}$, reflecting a mixture of the crust-derived noble gas and the air noble gas. The oils from the Gang 159 well, Xixin35-5 well and Xi 1-5-2 well have ${ }^{3} \mathrm{He} /{ }^{4} \mathrm{He}$ values of $1.83 \times 10^{-6}$, $1.63 \times 10^{-6}$ and $1.45 \times 10^{-6}$, respectively, which are higher than that of air, indicating a mixture of the crust-derived, mantle-derived and airderived noble gases. Based on the relation formula between the ${ }^{3} \mathrm{He} /{ }^{4} \mathrm{He}$ and ${ }^{4} \mathrm{He} /{ }^{20} \mathrm{Ne}$ ratios (Ishibashi et al., 2002) the proportion of noble gases without air contamination could be estimated. By estimation, the percent of the man- tle - derived noble gases varies from $11.48 \%$ to $16.80 \%$, averaging $14.12 \%$ (4). In comparison with noble gases of the crust type and the crust-mantle composite type, an obvious feature is that noble gases of this type have a mixture with air.

The noble gas datum of the oil from the Gang 556 well is plotted between the crude oil noble gases of the air-mixed type and the crustderived type (fig. 4), representative of a mixture of the air mixed and the crust-derived noble gases, namely the proportion of the air-derived noble gases is lower than that of the air-mixed noble gas.

\section{2. ${ }^{40} \mathrm{Ar} /{ }^{36} \mathrm{Ar}$ versus ${ }^{4} \mathrm{He}{ }^{20} \mathrm{Ne}$}

${ }^{36} \mathrm{Ar}$ is considered the original component of the Earth and ${ }^{40} \mathrm{Ar}$ is formed by the decay of ${ }^{40} \mathrm{~K}$, whose rate of production has an exponentially functional relation with time, therefore the natural gas ${ }^{40} \mathrm{Ar} /{ }^{36} \mathrm{Ar}$ ratio has an evident correlation with source rock age, i.e., the aging effect (Liu Wenhui and Xu Inching, 1993). By using the natural gas ${ }^{40} \mathrm{Ar} /{ }^{36} \mathrm{Ar}$ aging effect, source rock age can be estimated. The total Ar concentration in natural gas ranges from $n \times 10^{-3}$ to $n \times 10^{-5}$, however, that in air is $0.93 \%$, near $1 \%$. Therefore if $1 \%$ of air Ar is mixed in natural gas, its content will be several times or several ten times greater than that in natural gas, so that the natural gas ${ }^{40} \mathrm{Ar} /{ }^{36} \mathrm{Ar}$ ratio will obviously be reduced (Xu Yongchang et al., 1998). Thus the ${ }^{40} \mathrm{Ar} /{ }^{36} \mathrm{Ar}$ ratio is a sensitive indicator of air contamination in natural gas.

As mentioned above, the ${ }^{4} \mathrm{He} /{ }^{20} \mathrm{Ne}$ ratio is also an effective indicator of air contamination of crude oil and natural gas, therefore, through the search for ${ }^{40} \mathrm{Ar} /{ }^{36} \mathrm{Ar}$ and ${ }^{4} \mathrm{He} /{ }^{20} \mathrm{Ne}$ ratios, gas source age can be estimated after air contamination is excluded. Figure 6 displays the relation between crude oil ${ }^{40} \mathrm{Ar} /{ }^{36} \mathrm{Ar}$ and ${ }^{4} \mathrm{He} /{ }^{20} \mathrm{Ne}$ ratios. For convenient correlation, the noble gas ${ }^{40} \mathrm{Ar} /{ }^{39} \mathrm{Ar}$ data of the other oil fields in the Huanghua depression are also compiled in fig. 6. Table I and fig. 6 show that the natural gas and crude oil noble gases can be classified into the aging type and the air mixed type based on ${ }^{40} \mathrm{Ar} /{ }^{36} \mathrm{Ar}$ and ${ }^{4} \mathrm{He} /{ }^{20} \mathrm{Ne}$ ratios. 


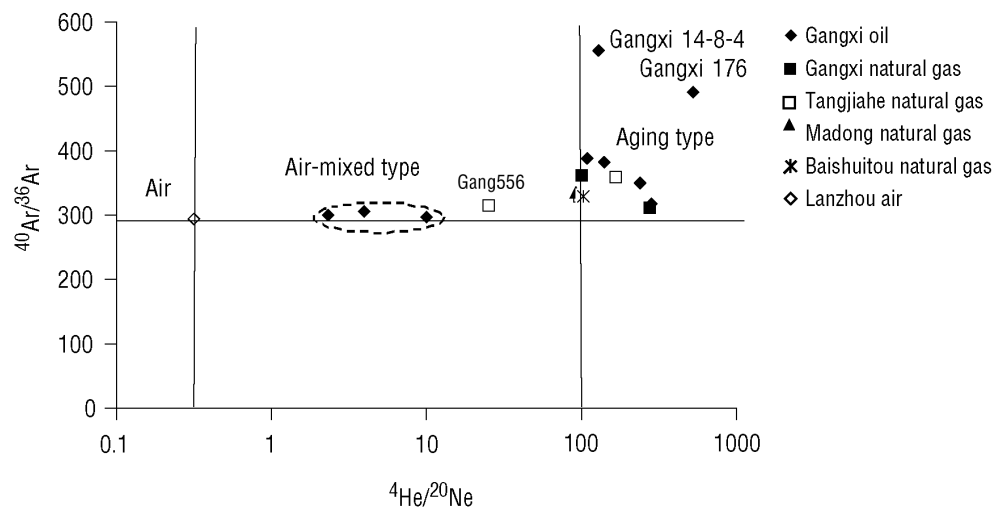

Fig. 6. Plot of ${ }^{40} \mathrm{Ar} /{ }^{36} \mathrm{Ar}$ versus ${ }^{4} \mathrm{He} /{ }^{20} \mathrm{Ne}$ of the crude oil from the Gangxi oil field.

\subsubsection{Aging type}

The ${ }^{4} \mathrm{He} /{ }^{20} \mathrm{Ne}$ ratio of this type of noble gases ranges from 92.5 to 527.0 , averaging 188.6 (12), which are two or three orders of magnitude higher than the air ${ }^{4} \mathrm{He} /{ }^{20} \mathrm{Ne}$ ratio (Air ${ }^{4} \mathrm{He} /{ }^{20} \mathrm{Ne}=0.318$ ). Coupled with ${ }^{40} \mathrm{Ar} /{ }^{36} \mathrm{Ar}$ distribution, the influence of air contamination on ${ }^{40} \mathrm{Ar} /{ }^{36} \mathrm{Ar}$ of this type can be negligible. The ${ }^{40} \mathrm{Ar} /{ }^{36} \mathrm{Ar}$ ratio of this type varies from 310.7 to 555.0 with an average of 375.9 (12). Based on the mantle $\mathrm{Ar} / \mathrm{He}$ ratio (0.83) (Xu Yongchang et al., 1998) and the estimation that the highest mantle He proportion of the Gangxi oil accounts for $32 \%$, the calculated mantle Ar concentration is $2.5 \times 10^{-5}$; therefore, its influence on the sample Ar contribution can be negligible. This is supported by the fact that the ${ }^{40} \mathrm{Ar} /{ }^{36} \mathrm{Ar}$ ratio of the most Gangxi crude oils and natural gases is similar to those in the Tanjiahe, Madong, and Baishuitou oil fields where the crust noble gas is dominant in crude oils. Therefore, the crude oil ${ }^{40} \mathrm{Ar} /{ }^{39} \mathrm{Ar}$ ratio from the Gangxi field is mainly of a crustal origin and can reflect an aging effect. By using ${ }^{40} \mathrm{Ar} /{ }^{36} \mathrm{Ar}$ the source rock age of the Gangxi oil field can be estimated. According to the conclusions reached by Xu Yongchang et al. (1998) who summarized the ${ }^{40} \mathrm{Ar} /{ }^{36} \mathrm{Ar}$ distributions of the Chinese natural gases from the source rocks with different geological ages, the ${ }^{40} \mathrm{Ar} /{ }^{36} \mathrm{Ar}$ ratio of the Chinese Tertiary natural gases varies from 302 to 600 . The six crude oils from the Gangxi oil field have ${ }^{40} \mathrm{Ar} /{ }^{36} \mathrm{Ar}$ ratios from 317.0 to 555.0, averaging 413.7 (6), therefore, they should be derived from the Tertiary source rocks, which is consistent with the conclusion reached according to the oil source correlation of biomarkers.

\subsubsection{Air-mixed type}

Different from the above type, the ${ }^{4} \mathrm{He} /{ }^{20} \mathrm{Ne}$ ratio of this type of crude oil noble gases ranges from 2.3 to 21.0 , averaging 9.3 (4), which is only one to two orders of magnitude larger than that of air $\left({ }^{4} \mathrm{He} /{ }^{20} \mathrm{Ne}=0.318\right)$. In combination with their ${ }^{40} \mathrm{Ar} /{ }^{36} \mathrm{Ar}$ ratios, it could be inferred that this type of the crude oil noble gases is heavily contaminated by air. The ${ }^{40} \mathrm{Ar} /{ }^{36} \mathrm{Ar}$ ratios of the oils from the Gang 195 well, the Xixin 35-5 well and the Xi 1-5-2 well are 305, 299 and 297 respectively, near to that of air, characteristic air contamination.

The noble gas datum of the natural gases from the Gang 556 well in fig. 6 falls between the air-mixed type and the aging type, representative of a mixture of the two types of the crude oil noble gases.

\subsection{Relation of crude oil noble gases to water injection}

Through the research on the noble gases of over 500 Chinese natural gas samples, $\mathrm{Xu}$ 
Yongchang (Xu Yongchang et al., 1998) concluded that the natural gas noble gases from wells without water injection were mainly derived from the mantle and the crust, therefore, the air derived noble gas in these natural gases could be negligible. Recently, we analyzed the noble gas isotopes of natural gases from 18 wells without water injection in the Zhongbu gas field and the Suligemiao gas field in the Ordos Basin and found that these samples had ${ }^{4} \mathrm{He} /{ }^{20} \mathrm{Ne}$ values larger than 1000 , suggesting a negligible contribution of the air derived noble gases to these natural gases and further supporting the above view. In this contribution noble gases in the oils and gases from the Madong, Baishuitou and Tangjiahe oil fields where water is not injected into wells are not air contaminated (table I). However, the Gangxi oil field has a long developing history and $2 / 3$ of its oil reserves have been exploited. To improve oil recovery, the measure of water injection has been taken in some wells. During water injection in the Gangxi oil field air noble gases are inevitably carried into wells by water, which contaminates the noble gases in the oils and gases.

Besides, from the analytical results in table I it can be seen that the situation of air contamination in the crude oil noble gases from the Gangxi oil field is complicated. Of the wells with water injection, the noble gases in oil and gases from some wells are attributed to an air-mixed type, e.g., Xixin35-5 well and Xi35-5-1 well, however those from the other wells are attributed to a crust type or a crust-mantle composite type, e.g., Xi159-1 well, Xi14-8-4 well and Xi34-5-1 well (table I, figs. 3 and 4). Of the wells without water injection, the noble gases from oils and gases of the Xi14-8well, Gangxi176well and Xi3-7-1 are not air contaminated, but those from Gang159 well and Xi1-5-2 well are air contaminated (table I, figs. 3 and 4). Therefore it could be deduced that whether crude oil noble gases had been air contaminated depends not only on water injection but also on the connectivity of productive formations and the effect of water injection. This inspires us that the noble gases from oils and gases might be of a great applicable potential in identifying the possibility of water injection, the connectivity of productive formations, and the effect of water injection.

\section{Conclusions}

Taking the Gangxi oil field as an example, the characteristics of the crude oil noble gases were investigated and their tracing implication were discussed. The research shows that:

i) The ${ }^{3} \mathrm{He} /{ }^{4} \mathrm{He}$ ratio of the six crude oils from the Gangxi oil field is characteristic of a mantle contribution. The percent of the mantlederived gases averages $24.1 \%$, suggesting that the Gangxi oil field has a tectonic background for the contribution of the mantle helium and its geothermal flow values average $75.0 \mathrm{mWm}^{-2}$.

ii) The six crude oils from the Gangxi oil field have an average ${ }^{40} \mathrm{Ar} /{ }^{36} \mathrm{Ar}$ ratio of 413.7, which is larger than that of air (297.5), basically characteristic of an aging effect. Based on this inference, the Gangxi oil should be derived from the tertiary source rocks.

iii) The existence of the air-mixed type of the crude oil noble gases in the Gangxi oil field could be attributed to water injection. The crude oil ${ }^{4} \mathrm{He} /{ }^{20} \mathrm{Ne},{ }^{3} \mathrm{He} /{ }^{4} \mathrm{He}$ and ${ }^{40} \mathrm{Ar} /{ }^{36} \mathrm{Ar}$ distributions are of great potential in investigating the water injection effect and the linkage of productive formations.

The research also shows that the tracing of oils by noble gases is similar to that of natural gases. By using crude oil ${ }^{3} \mathrm{He} /{ }^{4} \mathrm{He},{ }^{40} \mathrm{Ar} /{ }^{36} \mathrm{Ar}$ and ${ }^{4} \mathrm{He} /{ }^{20} \mathrm{Ne}$ ratios one cannot only trace oil gas sources, but also gain information on the water injection effect during the development of oil fields. Researching crude oil noble gas provides a new tool for identifying gas source, tectonic backgrounds, geothermal flow, gas/oil sources and water injection effect.

\section{Acknowledgements}

This contribution was financed by the Chinese National Natural Science Foundation (Grant No. 40172053), Important Direction Project of Knowledge Innovation in Resource and Environment Field, Chinese Academy of Sciences (Grant No. KZCX3-SW-128), and the foundation of the State Key Laboratory of Gas Geochemistry. We also thank the Research Institute of Petroleum Exploration and Development, Dagang Petroleum Group, for assistance in sampling in oil fields. 


\section{REFERENCES}

Battani, A., P. Sarda and A. Prinzhofer (2000): Basin scale natural gas source, migration and trapping traced by noble gases and major elements: the Pakistan Indus Basin, Earth Planet. Sci. Lett., 181, 229-249.

Clarke, W.B, W.J. Jenkins and J. Top (1976): Determination of the Tritium by mass spectrometric measurement of ${ }^{3} \mathrm{He}$, Int. J. Appl. Radiat. Isot., 27, 515-522.

Gulec, N., D.R. Hilton and H. MutLu (2002): Helium isotope variations in Turkey: relationship to tectonics, volcanism and recent seismic activities, Chem. Geol., 187, 129-142.

Ishibashi, J., M. SATO, Y. SANO, H. WAKITA, T. GAMO and W.C. Shanks (2002): Helium and carbon gas geochemistry of pore fluids from the sediment-rich hydrothermal system in Escanaba Trough, Appl. Geochem., 17, 1457-1466.

JENDEN, P.D. and I.R. KAPLAN (1989): Origin of natural gas in the Sacramento Basin, California, Am. Ass. Petrol. Geol. Bull., 73, 431-453.

Jinxing, D., S. Yan, D. Chunsheng, C. Anfu, S. MinGLIANG and L. YONGSHEN (1995): Inorganic Gases and their Pool-Forming Conditions in Eastern China (Beijing: Science Press), 62-200 (in Chinese).

KANEOKA, I. and N. TAKAOTA (1985): Noble gas state in the earth's interior-some constraints on the present state, Chemical. Geol., 52, 75-95.

Mingliang, S. (1991): Mass spectrum of helium isotope in natural gases, Bull. Anal. Test, 19, 50-55 (in Chinese).

MingLiAnG, S. (1995): Mass spectrum of helium isotope in water, Acta Mass Spectrum, 16, 34-38 (in Chinese).

Mingxing, T., X. Yongchang, S. Ping and L. Wenhui (1996): Tectonic, geochemical characteristics and pool-forming conditions in accumulation belts of mantle gas pools in eastern China, Sci. Ch., 26 (D), 531536 (in Chinese).

Oxburgh, E.R. and R.K. O’Nions (1987): Helium loss, tectonics and the terrestrial heat budget, Sci., 237, 1583-1588.

Pinti, D. and B. Marty (1995): Noble gases in crude oils from the Paris Basin, France: Implications for the origin of fluids and constraints on oil-water-gas interactions, Geoch. Cosmoch. Acta, 59, 3389-3404.

POLYAK, B.G., E.M. Prasolov, V. CERMAK and A.B. VERKHOVSKIY (1985): Isotopic compositions of noble gases in geothermal fluids of the Krusne Hary Mts., Czechoslovakiy, and the nature of the local geothermal anomaly, Geochim. Cosmochim. Acta, 49, 695-699.

PoredA, R.J., P.D. JENDEN, I.R. KAPLAN and H.CRAiG (1986): Mantle helium in Sacramento Basin natural gas wells, Geochim. Cosmochim. Acta, 50, 2847-2853.

Torgersen, T. and B.M. Kennedy (1999): Air-Xe enrichments in Elk Hills oil field gases: role of water in migration and storage, Earth Planet. Sci. Lett., 167 (3/4), 239-253, 1999.

Wakita, H., Y. SANO, A. Urabe and Y. NAKAmura (1990): Origin of methane-rich natural gas in Japan: formation of gas fields due to large-scale submarine volcanism, Appl. Geochem., 5, 263-278.

Wenhui, L. and X. YongCHANG (1993): Significance of He and $\mathrm{Ar}$ isotopic compositions in natural gases, Chin. Sci. Bull., 38, 818-821.

Yongchang, X., S. Ping, T. Mingxing and L. Wenhui (1996a): Mantle helium geochemistry in natural gases in Eastern Chinese petroleum province, I. A new type of helium resource: industrial accumulations in sedimentary layers in the crust, Sci. Ch., 26 (D), 1-8 (in Chinese).

Yongchang, X., S. Ping, T. Mingxing and L. Wenhui (1996b): Mantle helium geochemistry in natural gases in Eastern Chinese petroleum province, II. Helium, Argon and hydrocarbons, Sci. Ch., 26 (D), 187-192 (in Chinese).

Yongchang, X., S. Ping, L. Wenhui, T. Mingxing, S. MinGLIANG and D. JiANGOU (1998): Noble Gas Geochemistry in Natural Gases (Science Press, Beijing), 97-227 (in Chinese). 